\title{
Cross-cultural adaptation and validation of the Arabic version of the Physical Activity Scale for the Elderly among community-dwelling older adults in Saudi Arabia
}

This article was published in the following Dove Press journal:

Clinical Interventions in Aging

\author{
Ayidh M Alqarni ${ }^{1,2}$ \\ Vishal Vennu' \\ Sulaiman A Alshammari ${ }^{3}$ \\ Saad M Bindawas' \\ 'Department of Rehabilitation \\ Sciences, College of Applied Medical \\ Sciences, King Saud University, Riyadh, \\ Saudi Arabia; ${ }^{2}$ Department of Physical \\ Therapy, King Abdullah Hospital, Bisha, \\ Saudi Arabia; ${ }^{3}$ Department of Family \\ and Community Medicine, College \\ of Medicine, King Saud University, \\ Riyadh, Saudi Arabia
}

Purpose: Older adults are the fastest growing population group worldwide. Regular physical activity (PA) is reported to reduce the risk of health conditions and improve personal well-being. Few validated instruments can be used to measure the PA levels among older adults in Saudi Arabia. The Physical Activity Scale for the Elderly (PASE) is used worldwide for evaluating the PA levels of the elderly in epidemiological studies. However, this scale has not been translated into Arabic. This study aimed to cross-culturally adapt the PASE into Arabic language and evaluate its reliability and validity among community-dwelling older adults in Saudi Arabia.

Patients and methods: This study was a cross-sectional one following Beaton guidelines to translate and perform cultural adaptation, as well as test the reliability and validity of the PASE Arabic version (PASE-A). Elderly ( $\mathrm{N}=74)$ people from both genders, who lived in a community dwelling in Riyadh city, were selected from several primary health care centers. The study used Cronbach's alpha coefficient to assess the internal consistency reliability, while intraclass correlation coefficient $\left(\mathrm{ICC}_{2,1}\right)$ was used for test-retest reliability and the Spearman's rank correlation coefficient $(r)$ was used to evaluate the correlation among PASE-A and grip strength, Timed Up and Go test, body mass index, and fat percentage.

Results: Out of 74 older adults, 59 (79.7\%) completed the PASE-A questionnaire twice. The internal consistency of the PASE-A components was good (Cronbach's alpha 0.70-0.75), and the reliability of the components was excellent $\left(\mathrm{ICC}_{2,1}\right.$ 0.90-0.98). A higher PASE-A score was associated with higher grip strength $(r=0.28, p=0.05)$ and with shorter Timed Up and Go test times $(r=-0.45, p=0.01)$.

Conclusion: The PASE-A version was easy, understandable, and relevant for Saudi older adults' culture. This scale was a reliable and valid tool for evaluating and assessing the PA level among community-dwelling older adults in Saudi Arabia.

Keywords: physical activity, elderly, psychometric, PASE, Saudi Arabia, reliability, crosssectional study, psychometric

\section{Introduction}

Older adults form a substantial and rapidly growing segment of the population globally, ${ }^{1}$ including the Arab world, ${ }^{2}$ especially in Saudi Arabia. ${ }^{3}$ The number of older adults worldwide is predicted to increase by $300 \%$ between 2000 and 2025 , reaching its highest level in the Arab world by 2050. ${ }^{1,2}$ In 2014, the United Nations predicted that the older population of Saudi Arabia would continue to increase to be $18.4 \%$ of the total population by $2050 .{ }^{4}$ This suggests that there is a continuous growth of older people 
in Saudi Arabia due to the increase in life expectancy and decline in fertility rates. ${ }^{2}$ There are few high-quality data on the physical activity (PA) levels in older adults in the Arab world, ${ }^{5}$ including Saudi Arabia. ${ }^{3}$

Regular PA is widely considered to reduce the risk of many health conditions and contribute toward personal wellbeing. ${ }^{6}$ According to the World Health Organization, physical inactivity was the fourth leading risk factor for mortality and accounted for $6 \%$ of all deaths globally. ${ }^{7}$ In addition, physical inactivity is a leading cause of age-associated disorders, ${ }^{8,9}$ such as coronary artery disease, stroke, diabetes mellitus, hypertension, obesity, and low skeletal muscle mass.

There is limited availability of validated instruments that can be used to measure PA levels of elderly individuals in Saudi Arabia. Questionnaires are considered the best way to do this because they are easy to administer and cost-efficient. ${ }^{10}$ Instruments used to conduct epidemiological surveys of the elderly should include low-intensity (housework) and leisure (sport, recreation) activities; ${ }^{11}$ there are several questionnaires specifically designed for the elderly population that are used by many countries, including the Yale Physical Activity Survey, ${ }^{12}$ the Modified Baecke Questionnaire for older adults, ${ }^{13}$ the Zutphen Physical Activity Questionnaire, ${ }^{14}$ the Longitudinal Aging Study Amsterdam Physical Activity Questionnaire,${ }^{15}$ and the Physical Activity Scale for the Elderly (PASE). ${ }^{16}$ These measures differ in their intended purpose, suitability for different populations, and ability to assess the critical dimensions of PA (frequency, intensity, and time) in older adults. ${ }^{17-19}$

The PASE was selected for adaptation into Arabic due to the following reasons: 1) it is used worldwide for evaluating the PA levels of elderly people in epidemiological studies; 2) lowintensity activities are included (eg, housework); 3) it can be completed in 5-15 minutes; 4) the recall timeframe is not extended ("the last 7 days"); and 5) it can be self- or intervieweradministered. This scale was developed by the New England Research Institute (NERI) and introduced by Washburn et al. ${ }^{16}$ It consists of a 12-item questionnaire addressing strength and endurance exercise, sports activities, job activities, walking, yard work, care for other people, household activities, and outdoor gardening over the past 7 days. This scale has been translated and validated in different languages, including Dutch, ${ }^{20}$ Norwegian, ${ }^{21}$ Japanese, ${ }^{22}$ Korean, ${ }^{23}$ Chinese,${ }^{24}$ Chinese-Taiwan, ${ }^{25}$ German, ${ }^{26}$ Turkish, ${ }^{27}$ and Malay. ${ }^{28}$

\section{Objective}

The purpose of this study was to cross-culturally adapt the PASE into Arabic language and evaluate its reliability and validity among community-dwelling older adults in Saudi Arabia.

\section{Patients and methods \\ Translation process}

A license agreement from the NERI (the copyright owner) was obtained to use the original PASE questionnaire for translation into the Arabic language. The PASE Arabic version (PASE-A) was translated into six stages (Figure 1), as recommended by the guidelines published by Beaton et al. ${ }^{29}$

During stage I, forward translation from English into Arabic was completed independently by two bilingual, native Arabic speakers with an excellent understanding of English. One translator was a physiotherapist and the other was a professional translator. A written report for each translated version with translators' comments and the rationale for choices for problematic questions were submitted to an expert committee (see the description of stage IV in the following section).

During stage II, the two translated documents were synthesized into one Arabic version after resolution of all discrepancies between translators. A written report for the integrated version was also submitted to the expert committee.

For stage III, back-translation of the synthesized Arabic version into English was completed separately by two native English speakers, with each of them submitting a report to the expert committee.

During stage IV, an expert committee, consisting of four experts in research methodology, language translation, geriatrics, and rehabilitation, was formed to evaluate all the translated versions and review all submitted written reports. After evaluation and review, the committee reached a consensus on all discrepancies, and a prefinal version of PASE-A was formulated.

For stage $\mathrm{V}$, the prefinal version was tested on a sample of 30 community-dwelling older adults (mean age: 65.7 years, SD 8.8) to ensure that all of the contents could be understood. Issues were encountered relating to wording, clarity, and relevance to aid cultural understanding; several items were modified in the translated version. Under leisure time activity, item two, "walking the dog" was changed to "walking to the mosque"; under item three, some examples such as "bowling", "golf with a cart", "shuffleboard", and "fishing from a boat" were replaced with "shooting", "bowling", "billiards", and "simple care for pet animals", respectively; item four "ballroom dancing" was modified to "folk dancing with slow movement", and "ice skating", "golf without a cart", and "softball" were replaced with "grazing sheep or 


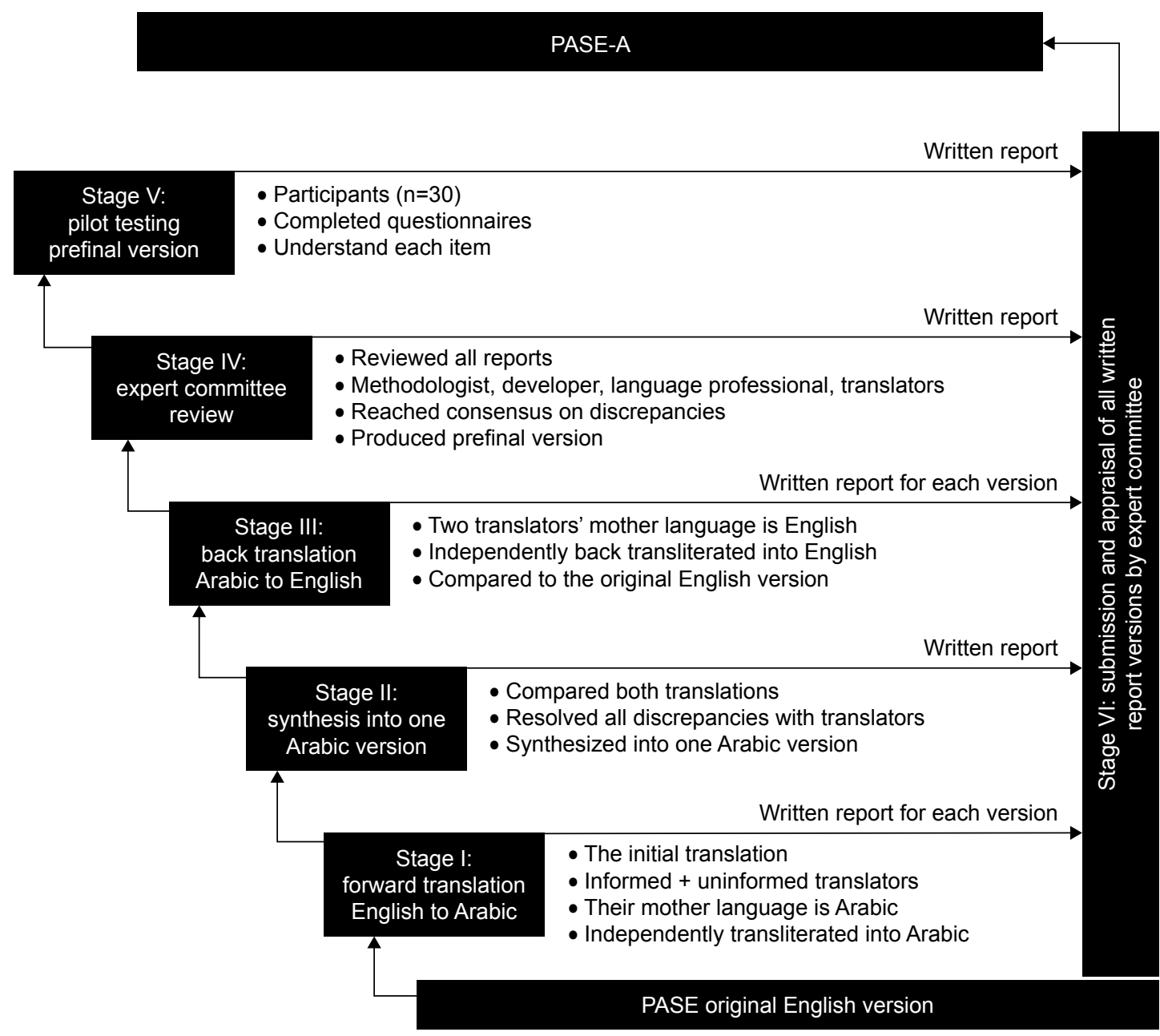

Figure I Flowchart of the translation and cross-cultural adaptation process of PASE-A from the original English version.

Abbreviations: PASE, Physical Activity Scale for the Elderly; PASE-A, Arabic version of the Physical Activity Scale for the Elderly.

camels", respectively; and under item five, some examples such as "single tennis" and "skiing downhill or cross-country" were removed, and "aerobic dance" was modified to "folk dancing with high movement". Under household activity the examples at item nine - regarding lawn work or yard care - "snow removal" was replaced with "dusting or washing dust", and "wood chopping" was removed. Under workrelated activity, units of weight were changed from pounds to kilograms. As the PASE-A version consists of only 12 items, 30 patients were considered sufficient for validation. ${ }^{29}$ As part of stage VI, all translated versions were sent to the developer (NERI) for approval of the final PASE-A version.

\section{Study design}

A cross-sectional study was designed to evaluate the psychometric properties of the PASE-A version among communitydwelling older adults living in Riyadh, Saudi Arabia. The sample $(\mathrm{N}=74)$ was selected from different primary health care centers (PHCCs) across Riyadh, Saudi Arabia. PHCCs provide vital health care at the first level and aim to enhance an individual's health status by providing preventive and curative services. ${ }^{30}$

\section{Participants}

To enroll in this study, the study investigator called potential participants through a telephone after collecting their details from the PHCCs. Participants who accepted the invitation were informed about the purposes and procedures of the study before enrollment. Both men and women aged 60 years and above, who were independent in daily living and able to read and understand basic Arabic language were included. Individuals with severe pain or severe hearing or vision problems, with a diagnosis of Alzheimer's disease, a history of stroke in the past 2 years, uncontrolled cardiovascular disease, a documented cognitive disorder, or physical disability that could interfere or have an effect on data were excluded. 


\section{Ethics approval and informed consent}

The Research Ethics Committee and the Institutional Review Board at the following institutions authorized this study: College of Applied Medical Sciences and King Fahad Medical City (No: 17-004E). All participants gave written informed consent before participation. The participants were enrolled according to the quality criteria described by Terwee et al. ${ }^{31}$

\section{Data collection}

In the first week, all participants' demographic data, such as age, gender, education, occupation, a region in which the person was living, morbidity, and body mass index (BMI), were collected. Next, we asked all of them to complete the PASE-A questionnaire twice within a 1-week interval. Physical assessments, such as grip strength, the Timed Up and Go (TUG) test, BMI, and body composition (BC), were also completed for all participants.

\section{Measures}

The PASE-A questionnaire is are designed to measure selfreported PA among older adults in three domains (leisure, household, and work-related activities) over the preceding 7 days. ${ }^{16}$ This scaled score was calculated as the sum of the products of the time spent on an activity and the weighting of the activity (calculated separately for the 12 types of activities). For leisure activities, respondents were asked to respond to two ordinal ranked questions: frequency ( $1=$ never to $4=$ often) and duration ( $<1$ to $>4$ hours). Household and work-related activities were asked as categorical "yes or no" questions. Those who answered "yes" to a specific activity had a prespecified weight added to their score, while those who answered "no" received a score of zero for that question. Scale scores were calculated from weights and frequency values for all 12 items. Multiplying the activity weight by the activity frequency for every single item. Then, summing the (weight time frequency) for all 12 items to give the overall PASE score.

Grip strength of the dominant hand was measured three times in the standing position using a Jamar ${ }^{\circledR}$ hydraulic hand dynamometer (Patterson Corporation, Jackson, MI, USA). The mean of the three results was selected for the analysis. The Jamar hydraulic hand dynamometer has been shown to be a reliable and valid way to measure grip strength in

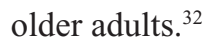

In the TUG test, each participant was asked to rise from an armchair (seat height $49 \mathrm{~cm}$ ), walk $3 \mathrm{~m}$, turn around $\left(180^{\circ}\right)$, and sit back down in the chair. ${ }^{33}$ The time was recorded in seconds using a stopwatch. One practice trial was performed, and assistive devices were allowed. TUG has been shown to be reliable and valid to measure balance, functional mobility, and fall risk in older adults. ${ }^{34}$

BMI was calculated by dividing the weight in kilograms by the square of the height in meters. Measures of BC, such as fat percentage (FP), fat-free mass (FFM), fat mass (FM), total body water (TBW), and muscle mass (MM), were analyzed using the Bioelectrical Impedance Analysis device (BC-418MA, BC Analyzer; Tanita, Tokyo, Japan). ${ }^{35}$

\section{Psychometric assessments and statistical analysis}

All participants' demographic data were presented as counts (percentage) or mean and SD, as appropriate. Cronbach's alpha was used to determine internal consistency. Alpha values from 0.70 to 0.95 were considered good to excellent. ${ }^{36}$ Test-retest reliability was determined using intraclass correlation coefficient $\left(\mathrm{ICC}_{2,1}\right)$. An ICC value equivalent to or $>0.70$ indicated a good level of reliability. ${ }^{37} \mathrm{~A}$ 1-week time interval was selected as it was short enough to ensure participants could not change their PA level and long enough to prevent recall bias. ${ }^{38}$ Absolute reliability was analyzed both by the standard error of measure (SEM) and the minimal detectable change (MDC). SEM was determined as the $\mathrm{SD}$ of the first test session scores $\times$ square root $\left(1-\mathrm{ICC}_{2,1}\right)$. MDC was determined as $\mathrm{MDC}=\mathrm{SEM} \times 1.96 \times \sqrt{ } 2$, where 1.96 was derived from the $0.95 \% \mathrm{CI}$. SEM represents the smallest change that indicates a real difference for a group of subjects, while MDC shows the smallest change that indicates a real improvement for a single subject. ${ }^{39,40}$

Construct validity of PASE-A (total score, subscale, and item-by-item) was evaluated using Spearman's rank correlation coefficients ( $r$ ), with grip strength, TUG, BMI, $\mathrm{BC}$, sociodemographic variables (age, education level, and occupational status), pain level, and morbidity. Coefficient values $>0.75$ and $0.25-0.75$ were considered good to excellent and fair to good, respectively. Statistical analyses were performed using statistical analysis software version 9.3 (SAS Institute, Cary, NC, USA) and Microsoft ${ }^{\circledR}$ Excel (Microsoft Corp., Redmond, WA, USA).

\section{Results}

\section{Participant's characteristics}

In total, 74 older adults (41 men and 33 women) participated in the validation of the PASE-A. Among them, 59 (79.7\%) older adults ( 31 men and 28 women) completed the PASE questionnaire twice. The participants' demographic and 
Table I Participants' demographic and clinical characteristics

\begin{tabular}{ll}
\hline Characteristics & $\begin{array}{l}\text { Total } \\
(\mathbf{N}=\mathbf{7 4})\end{array}$ \\
\hline Age (years), mean \pm SD & $65.0 \pm 7.1$ \\
Women, $\mathrm{n}(\%)$ & $33(45)$ \\
Level of education, $\mathrm{n}(\%)$ & \\
$\quad$ Primary school or lesser & $48(64.9)$ \\
$\quad$ Intermediate school or more & $26(35.1)$ \\
Occupation status, $\mathrm{n}(\%)$ & \\
$\quad$ None or retired & $65(87.8)$ \\
$\quad$ On job or freelance & $9(12.2)$ \\
Sector of the primary health care center, $\mathrm{n}(\%)$ & \\
$\quad$ East & $12(16.2)$ \\
$\quad$ North & $25(33.8)$ \\
$\quad$ South & $22(29.7)$ \\
$\quad$ Middle & $15(20.3)$ \\
Morbidity, n (\%) & \\
$\quad$ No & $15(20)$ \\
Yes $\geq I$ & $59(80)$ \\
BMl (kg/m²), mean $\pm S D$ & $29.4 \pm 5.3$ \\
Pain, mean $\pm S D$ & $1.9 \pm 2.3$ \\
Grip strength $(\mathrm{kg})$, mean $\pm S D$ & $21.0 \pm 8.6$ \\
Timed Up and Go test (m/s), mean $\pm S D$ & $12.3 \pm 3.4$ \\
Weight $(\mathrm{kg})$, mean $\pm S D$ & $75.5 \pm 13.3$ \\
\hline
\end{tabular}

Note: Values are presented in mean \pm SD or count (percentage).

Abbreviation: BMl, body mass index.

clinical characteristics are summarized in Table 1. The mean age of the study participants was $65.0 \pm 7.1$ years; most of them $(55 \%)$ were men. The majority of the participants had a primary school or lesser education (64.9\%) and one or more morbidities $(80 \%)$. A high proportion of the participants were from the northern region of Riyadh (33.8\%). However, the mean total PASE-A score was $111.7 \pm 77.7$. The total PASE-A score was significantly $(p<0.0001)$ higher among men (116.9 \pm 75.8$)$ compared to women $(105.2 \pm 80.8$; data not shown).

\section{Reliability}

PASE-A components were found to have adequate testretest reliablility, or the ICC between attempts was strong, indicating test-retest reliability ranged from 0.90 to 0.98 . Absolute reliability showed that the measurement error at the group level (SEM) was 3.3-8.5. The measurement error at the individual level (MDC) was 9.0-23.6. The internal consistency of the PASE-A components was good, with Cronbach's alpha ranging from 0.70 to 0.75 . The internal consistency of the "lawn work or yard care" item was fair; the Cronbach's alpha was 0.69 (Table 2).

\section{Construct validity}

Table 3 presents the correlation between the total PASE-A score, its components, and validation measures. The total PASE-A score was moderately correlated with grip strength $(r=0.288, p<0.05)$ and shorter TUG $(r=-0.451, p<0.01)$. A higher leisure time activity score was moderately correlated with higher grip strength ( $r=0.443, p<0.01$ ), higher FFM $(r=0.282, p<0.05)$, higher TBW percentage $(r=0.258$, $p<0.05)$, higher MM $(r=0.290, p<0.05)$, and reduced FP $(r=-0.258, p<0.05)$. A higher leisure time activity score

Table 2 Score distribution of the two assessments ${ }^{\mathrm{a}}$ with the results of the reliability analyses of internal consistency

\begin{tabular}{|c|c|c|c|c|c|c|}
\hline \multirow[t]{2}{*}{ PASE-A component } & \multicolumn{2}{|c|}{ PASE-A version } & \multirow[t]{2}{*}{ ICC $(95 \% \mathrm{Cl})$} & \multirow[t]{2}{*}{ SEM } & \multirow[t]{2}{*}{$\mathrm{MDC}_{95}$} & \multirow{2}{*}{$\begin{array}{l}\text { Cronbach's } \\
\text { alpha }\end{array}$} \\
\hline & $\begin{array}{l}\text { Test, } \\
\text { mean } \pm \text { SD } \\
(n=74)\end{array}$ & $\begin{array}{l}\text { Retest, } \\
\text { mean } \pm \text { SD } \\
(n=59)\end{array}$ & & & & \\
\hline \multicolumn{7}{|l|}{ Leisure time activity } \\
\hline Walk outside home & $23.5 \pm 24.3$ & $23.1 \pm 26.2$ & $0.90(0.85-0.94)$ & $5.01(3.05-6.97)$ & $13.89(\mid 1.93-15.85)$ & 0.71 \\
\hline Light sport & $\mathrm{I} .3 \pm 5.4$ & $1.4 \pm 4.2$ & $0.98(0.97-0.99)$ & $4.74(2.78-6.70)$ & $13.13(11.17-15.09)$ & 0.73 \\
\hline Moderate sport & $3.0 \pm 10.2$ & $1.9 \pm 6.6$ & $0.98(0.97-0.99)$ & $5.89(3.93-7.85)$ & $16.32(\mid 4.36-18.28)$ & 0.75 \\
\hline Strenuous sport & $0.9 \pm 3.1$ & $1.0 \pm 4.5$ & $0.98(0.97-0.99)$ & $3.27(1.31-5.23)$ & $9.06(7.10-11.02)$ & 0.71 \\
\hline Muscle strength/endurance exercises & $3.3 \pm 8.5$ & $3.2 \pm 11.6$ & $0.90(0.85-0.94)$ & $4.68(2.72-6.64)$ & $12.97(\mid 1.01-14.93)$ & 0.75 \\
\hline \multicolumn{7}{|l|}{ Household activity } \\
\hline Light housework & $12.2 \pm 12.6$ & $13.5 \pm 12.5$ & $0.98(0.97-0.99)$ & $3.61(1.65-5.57)$ & $10.0(8.04-11.96)$ & 0.72 \\
\hline Heavy housework or chores & $7.7 \pm 11.6$ & $6.8 \pm 11.2$ & $0.98(0.97-0.99)$ & $4.18(2.22-6.14)$ & $11.59(9.63-13.55)$ & 0.70 \\
\hline Home repairs & $4.4 \pm 10.7$ & $3.5 \pm 9.8$ & $0.98(0.97-0.99)$ & $5.10(3.14-7.06)$ & $14.14(12.18-16.10)$ & 0.71 \\
\hline Lawn work or yard care & $12.6 \pm 17.3$ & $9.1 \pm 15.8$ & $0.90(0.85-0.94)$ & $4.87(2.91-6.83)$ & $13.5 \mid(11.55-15.47)$ & 0.69 \\
\hline Outdoor gardening & $5.1 \pm 8.7$ & $4.0 \pm 8.1$ & $0.98(0.97-0.99)$ & $3.85(I .89-5.8 I)$ & $10.68(8.72-12.64)$ & 0.70 \\
\hline Caring for another person & $24.5 \pm 16.1$ & $24.3 \pm 16.2$ & $0.98(0.97-0.99)$ & $3.25(\mid .29-5.2 I)$ & $9.02(7.06-10.98)$ & 0.74 \\
\hline Work for pay or as a volunteer & $12.8 \pm 30.5$ & $8.3 \pm 25.4$ & $0.98(0.97-0.99)$ & $8.53(6.57-10.49)$ & $23.63(21.67-25.59)$ & 0.72 \\
\hline
\end{tabular}

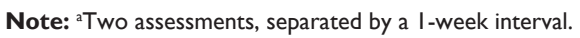

Abbreviations: ICC, intraclass correlation coefficient (two-way model, single measure); $\mathrm{MDC}_{95}$, minimal detectable change from the $95 \%$ CI level; PASE-A, Arabic version of the Physical Activity Scale for the Elderly; SEM, standard error of measurement. 
Table 3 Correlations between the PASE-A version and validation measures

\begin{tabular}{|c|c|c|c|c|}
\hline $\begin{array}{l}\text { Validation } \\
\text { measure }\end{array}$ & $\begin{array}{l}\text { Total } \\
\text { PASE } \\
\text { score, } \\
\mathbf{n}=74\end{array}$ & $\begin{array}{l}\text { Leisure } \\
\text { time } \\
\text { activity } \\
\text { score, } n=74\end{array}$ & $\begin{array}{l}\text { Household } \\
\text { activity } \\
\text { score, } \\
\text { n=74 }\end{array}$ & $\begin{array}{l}\text { Work- } \\
\text { related } \\
\text { activity, } \\
\mathrm{n}=74\end{array}$ \\
\hline Grip strength & $0.288^{*}$ & $0.443 * *$ & 0.080 & 0.182 \\
\hline TUG & $-0.45 I^{* *}$ & $-0.442 * *$ & $-0.272 *$ & $-0.282 *$ \\
\hline Weight & 0.213 & 0.123 & 0.147 & 0.154 \\
\hline BMI & 0.206 & -0.055 & $0.290 *$ & 0.044 \\
\hline Fat percent & 0.080 & $-0.258^{*}$ & $0.307^{* *}$ & -0.183 \\
\hline Fat mass & 0.169 & -0.094 & $0.278^{* *}$ & -0.030 \\
\hline FFM & 0.112 & $0.288^{*}$ & -0.114 & $0.311 * *$ \\
\hline TBW percent & -0.080 & $0.257^{*}$ & $-0.304 * *$ & 0.183 \\
\hline Muscle mass & 0.111 & $0.293^{*}$ & -0.118 & $0.312 * *$ \\
\hline
\end{tabular}

Notes: Bold values indicate statistically significant at $* p<0.05$ and $* * p<0.01$.

Abbreviations: BMI, body mass index; FFM, fat-free mass; PASE, Physical Activity Scale for the Elderly; PASE-A, Arabic version of the Physical Activity Scale for the Elderly; TBW, total body water; TUG, the Timed Up and Go test.

was moderately correlated with shorter TUG $(r=-0.442$, $p<0.01)$. A higher household activity score was moderately correlated $(p<0.05)$ with a higher BMI $(r=0.290)$, higher FP $(r=0.304, p<0.01)$, and higher FM $(r=0.278, p<0.01)$, as well as with shorter TUG $(r=-0.272, p<0.05)$ and lower TBW $(r=-0.307, p<0.01)$. A higher work-related activity score was moderately correlated $(p<0.01)$ with higher FFM $(r=0.311)$, higher MM $(r=0.312)$, and with shorter TUG $(r=-0.282, p<0.05)$.

Correlations between each item of the PASE-A and the validated measures are shown in Table 4 . The table shows moderate correlation $(p<0.01$ or $p<0.05)$ between some items $(2,5,7,8$, and $9 \mathrm{~d})$ and validation measures such as grip strength, BMI, and FP. A few items such as 2, 4, 9a, and 10 were moderately correlated $(p<0.01$ or $p<0.05)$ with shorter TUG.

Correlations of the total PASE-A and its subscales with sociodemographic variables, pain levels, and morbidity are presented in Table 5 . The total PASE-A was moderately correlated with age $(r=-0.246, p<0.05)$, pain $(r=-0.252, p<0.05)$, and morbidity $(r=-0.325, p<0.01)$. The PASE-A subscale of leisure time activity was moderately correlated with morbidity $(r=-0.277, p<0.05$ ), while household activity was moderately correlated (both $p<0.05)$ with age $(r=-0.230)$ and morbidity $(r=-0.292)$. The subscale work-related activity was moderately correlated (both $p<0.05$ ) with education $(r=0.262)$ and pain $(r=-0.230)$, while it was strongly correlated with occupation $(r=0.536, p<0.01)$.

\section{Discussion}

The current study used six stages recommended by Beaton guidelines to cross-culturally adapt the PASE into Arabic language and evaluate its psychometric properties with Arabic-speaking, community-dwelling older adults living in Riyadh, Saudi Arabia. The study's findings suggest that the PASE-A version was easy, understandable, and relevant for Saudi older adults' culture. This scale is a reliable and valid tool for evaluating and assessing the PA level among community-dwelling older adults in Saudi Arabia.

In this study, there were no difficulties experienced during translation. A recommended standard guideline was used for cultural adaptation to ensure the quality and equivalence of the PASE-A to the source material. In the adapted version, some of the items and examples were modified because of the Saudi Arabian cultural context, including its environment and elderly activities. For example, "walking the dog" and "wood chopping" did not overlap with habitual responsibilities or activities of elderly people in Saudi Arabia. Furthermore, "ice skating" and "snow removal" were modified because it does not snow in the country. The example of "golf without a cart, softball" was replaced with "grazing sheep or camels" because this example is a recreational habit of some older adults in Saudi Arabia. All modified or replaced examples were verified to match up with the extra examples provided by Ainsworth et al. ${ }^{41}$

The mean PASE-A score for older adults in this study was $111.7 \pm 77.7$. This is slightly higher than in previous

Table 4 Correlation between the PASE-A version items and validation measures

\begin{tabular}{|c|c|c|c|c|c|c|c|c|c|c|c|c|}
\hline \multirow{2}{*}{$\begin{array}{l}\text { Validation } \\
\text { measure }\end{array}$} & \multicolumn{12}{|c|}{ Item no of the PASE-A } \\
\hline & 2 & 3 & 4 & 5 & 6 & 7 & 8 & $9 a$ & $9 b$ & $9 c$ & 9d & 10 \\
\hline Grip strength & $0.379 * *$ & 0.151 & 0.200 & $0.252 *$ & 0.137 & $0 .-178$ & -0.005 & 0.146 & 0.121 & 0.186 & 0.093 & 0.182 \\
\hline TUG & $-0.503 * *$ & -0.092 & $-0.240 *$ & -0.139 & -0.070 & -0.003 & -0.226 & $-0.368 * *$ & -0.215 & -0.166 & -0.123 & $-0.282 *$ \\
\hline BMI & -0.032 & 0.102 & 0.138 & 0.038 & -0.013 & $0.303 * *$ & $0.234^{*}$ & 0.155 & 0.085 & 0.034 & $0.235^{*}$ & 0.044 \\
\hline Fat percent & $-0.245 *$ & 0.093 & 0.043 & -0.004 & -0.070 & $0.365 * *$ & $0.323 * *$ & -0.040 & 0.135 & -0.011 & $0.240 *$ & -0.183 \\
\hline
\end{tabular}

Notes: Item \#2, walk outside home; item \#3, light sport; item \#4 moderate sport; item \#5, strenuous sport; item \#6, muscle strength/endurance exercise; item \#7, light housework; item \#8, heavy housework or chores; item \#9a, home repairs; item \#9b, lawn work or yard care; item \#9c, outdoor gardening; item \#9d, caring for another person; item \#10, work for pay or as a volunteer. Bold values indicate statistically significant at $* p<0.05$ and $* * p<0.0$ I.

Abbreviations: BMI, body mass index; PASE-A, Arabic version of the Physical Activity Scale for the Elderly; TUG, Timed Up and Go test. 
Table 5 Correlations between the PASE-A, sociodemographic variables, pain, and morbidity

\begin{tabular}{|c|c|c|c|c|}
\hline Variable & $\begin{array}{l}\text { Total } \\
\text { PASE } \\
\text { score, } \\
n=74\end{array}$ & $\begin{array}{l}\text { Leisure } \\
\text { time } \\
\text { activity } \\
\text { score, } n=74\end{array}$ & $\begin{array}{l}\text { Household } \\
\text { activity } \\
\text { score, } \\
\text { n=74 }\end{array}$ & $\begin{array}{l}\text { Work-related } \\
\text { activity, } n=74\end{array}$ \\
\hline Age & $-0.246^{*}$ & -0.168 & $-0.230 *$ & -0.054 \\
\hline Education & 0.120 & 0.058 & 0.094 & $0.262 *$ \\
\hline Occupation & 0.152 & 0.083 & 0.006 & $0.536 * *$ \\
\hline Pain & $-0.252^{*}$ & -0.165 & -0.130 & $-0.230 *$ \\
\hline Morbidity & $-0.325 * *$ & $-0.277^{*}$ & $-0.292^{* *}$ & -0.019 \\
\hline
\end{tabular}

Notes: Bold values indicate statistically significant at $* p<0.05$ and $* * p<0.0$ I. Abbreviations: PASE, Physical Activity Scale for the Elderly; PASE-A, Arabic version of the Physical Activity Scale for the Elderly.

studies conducted in the USA $(102.9 \pm 61.1)^{16}$ and China $(104.4 \pm 47.1),{ }^{24}$ but is somewhat lower than in a study conducted in Japan (114.9 \pm 44.9$).{ }^{22}$ The internal consistency of the PASE-A components was good and comparable to the results reported in the original, ${ }^{16}$ as well as the Norwegian version, ${ }^{21}$ where it was tested among community-dwelling older adults (aged 67 years or older). However, the internal consistency of the PASE-A components and its items was somewhat higher than the source version. ${ }^{16}$ It is to be noted that this study evaluated the internal consistency of the PASE-A components and its items.

The test-retest reliability of the total PASE-A and its components was higher than the original, ${ }^{16}$ Japanese, ${ }^{22}$ Chinese, ${ }^{24}$ Chinese-Taiwanese, ${ }^{25}$ German, ${ }^{26}$ and Malay versions, ${ }^{28}$ but lower than the Norwegian version. ${ }^{21}$ To the best of our knowledge, few studies have examined the absolute reliability of the PASE..$^{26,42,43}$ However, PASE scores for healthy community-dwelling older adults have not been previously reported. The SEM and MDC values suggest reasonably high inter-test precision for sensitivity to individual or group differences in longitudinal studies.

Correlation analysis was used to construct validity between the PASE-A components, items, and validation measures. Correlation between the PASE-A questionnaires and validation measures was fair $(r=0.25-0.75)$. These findings were similar to those demonstrated in previous studies. For example, the correlations between grip strength and PASE scores for the original $(r=0.37)$, Chinese $(r=0.40),{ }^{24}$ Malay $(r=0.33),{ }^{28}$ and Korean versions ${ }^{23}(r=0.25)$ all fall in the "fair" range.

Our study found the total PASE-A score was inversely associated with the TUG. Our results suggest that PA levels decrease with increases in TUG for older adults. This inverse association was found in an assessment of the Chinese version, ${ }^{24}$ but using a different test (dynamic balance test).
Meanwhile, the original version ${ }^{16}$ found a positive association with a static balance test, suggesting that PA levels increase with increased static balance. These findings support the World Health Organization guidelines that promote the participation of older adults in regular PA to enhance stability and prevent falls and reduce the risk of falls. ${ }^{7}$

In this study, there was no correlation found between the total PASE-A score, BMI, FP, and other BC, which is similar to the original, ${ }^{16}$ Malay, ${ }^{28}$ and Chinese versions. ${ }^{24}$ Moreover, item three was not correlated with any of the validation measures. It may be that most of the participants, especially women, were not engaged enough in light sports activities. Also, item six had a few correlations due to the small numbers of enrollments involved in a light household activity, especially from the male side. However, positive associations were found between household activity, BMI, FP, and FM. These correlations may be due to participants spending more time at home doing light household activities. ${ }^{44}$

One of the most interesting findings of this study was that the PASE-A score was negatively associated with age, pain, and morbidity. This inverse correlation is similar to the literature, suggesting that age, pain, and morbidity may alter the PA levels among older adults. ${ }^{45-47}$ Thus, addressing the relationship between pain, morbidity, and PA levels among older adults is warranted in further investigation.

Limitations of this study must be considered. A small sample size from the PHCCs across Riyadh might limit the generalizability of the study findings. Also, additional explanation may be needed about the intensity of sports and recreational activities, which may have introduced some bias. In our study, we used both self-reported and intervieweradministered in-person interview methods to collect data and the agreement between them has not been tested yet. Finally, the translated version used classic Arabic; some terms may vary because of differences in the dialects of the Arabic language between regions of the country as well as between nations.

Strengths of this study are that it included an adequate sample of community-dwelling older adults, consistent with previous literature, ${ }^{16,22,24}$ and had high response rate (79.7\%) on the second assessment. Translation and cultural adaptation were performed according to the standard guidelines. ${ }^{29}$ Objective measures were used in validation of the PASE-A. Finally, the PASE-A questionnaire was specially designed to study PA levels among older adults in Saudi Arabia, which were not available previously.

This study showed that the PASE-A is a reliable and valid questionnaire that enables researchers to estimate PA levels 
among community-dwelling older adults in Saudi Arabia. The adapted questionnaire also allows clinicians to design an adequate PA program for individuals with low PA levels. Moreover, researchers, policymakers, and stakeholders should consider the PASE-A version because of its low cost, the short time required to complete it, and its suitability to Saudi culture, environment, and elderly activities. By recommendations from a systematic review of the literature, ${ }^{48}$ our new PASE-A questionnaire addresses the PA levels among older adults in Saudi Arabia because the questionnaire items were carefully developed and are most appropriate to address older adults' activities and participation.

\section{Conclusion}

The PASE-A was a well-accepted, reliable, and valid tool for evaluating and assessing the PA levels among communitydwelling older adults in Saudi Arabia. Further studies are needed to investigate the use of the PASE-A in other Arab countries to determine the validity of their older individuals. More extensive studies of PASE-A are necessary to develop normative PA data among Saudi older adults because a reliable and valid assessment of PA levels in older adults is an essential area of research.

\section{Acknowledgments}

The authors extend their appreciation to the Research Centre, College of Applied Medical Sciences, and the Deanship of Scientific Research at King Saud University for funding this research.

\section{Disclosure}

The authors report no conflicts of interest in this work.

\section{References}

1. Keith KD. Cross-Cultural Psychology: Contemporary Themes and Perspectives. Chichester, West Sussex, UK; Malden, MA: Wiley-Blackwell; 2011.

2. Khraif R, Salam A, Elsegaey I, AlMutairi A. Changing age structures and ageing scenario of the Arab world. Soc Indic Res. 2015;121:763-785.

3. Karlin NJ, Weil J, Felmban W. Aging in Saudi Arabia: an exploratory study of contemporary older persons' views about daily life, health, and the experience of aging. Gerontol Geriatr Med. 2016;2: 2333721415623911.

4. Abyad A. From the editor: geriatrics in the middle east. ME-JAA. 2004; $1(1): 1-10$.

5. Abdulrahim S, Ajrouch KJ, Jammal A, Antonucci TC. Survey methods and aging research in an Arab sociocultural context-a case study from Beirut, Lebanon. J Gerontol B Psychol Sci Soc Sci. 2012;67(6):775-782.

6. Scarborough P, Bhatnagar P, Wickramasinghe KK, Allender S, Foster C, Rayner M. The economic burden of ill health due to diet, physical inactivity, smoking, alcohol and obesity in the UK: an update to 2006-2007 NHS costs. J Public Health (Oxf). 2011;33(4):527-535.

7. World Health Organization. Global Recommendations on Physical Activity for Health. Geneva:WHO Press; 2010.
8. Milanovic Z, Pantelic S, Trajkovic N, Sporis G, Kostic R, James N. Age-related decrease in physical activity and functional fitness among elderly men and women. Clin Interv Aging. 2013;8:549-556.

9. King HA, Gierisch JM, Williams JW Jr, Maciejewski ML. Effects of Health Plan-Sponsored Fitness Center Benefits on Physical Activity, Health Outcomes, and Health Care Costs and Utilization: A Systematic Review. Washington (DC):Department of Veterans Affairs; 2012.

10. LaPorte RE, Montoye HJ, Caspersen CJ. Assessment of physical activity in epidemiologic research: problems and prospects. Public Health Rep. 1985;100(2):131-146.

11. Gellert P, Ziegelmann JP, Krupka S, Knoll N, Schwarzer R. An agetailored intervention sustains physical activity changes in older adults: a randomized controlled trial. Int J Behav Med. 2014;21(3):519-528.

12. Schuler PB, Richardson MT, Ochoa P, Wang MQ. Accuracy and repeatability of the Yale physical activity survey in assessing physical activity of older adults. Percept Mot Skills. 2001;93(1):163-177.

13. VoorripsLE, RavelliAC, Dongelmans PC, DeurenbergP, VanStaverenWA. A physical activity questionnaire for the elderly. Med Sci Sports Exerc. 1991;23(8):974-979.

14. Caspersen CJ, Bloemberg BP, Saris WH, Merritt RK, Kromhout D. The prevalence of selected physical activities and their relation with coronary heart disease risk factors in elderly men: the Zutphen Study, 1985. Am J Epidemiol. 1991;133(11):1078-1092.

15. Stel VS, Smit JH, Pluijm SM, Visser M, Deeg DJ, Lips P. Comparison of the LASA physical activity questionnaire with a 7-day diary and pedometer. J Clin Epidemiol. 2004;57(3):252-258.

16. Washburn RA, Smith KW, Jette AM, Janney CA. The physical activity scale for the elderly (PASE): development and evaluation. J Clin Epidemiol. 1993;46(2):153-162.

17. Rikli RE. Reliability, validity, and methodological issues in assessing physical activity in older adults. Res Q Exerc Sport. 2000;71(2 Suppl): S89-S96.

18. Shephard RJ. Limits to the measurement of habitual physical activity by questionnaires. Br J Sports Med. 2003;37(3):197-206; discussion 206.

19. Murphy SL. Review of physical activity measurement using accelerometers in older adults: considerations for research design and conduct. Prev Med. 2009;48(2):108-114.

20. Schuit AJ, Schouten EG, Westerterp KR, Saris WH. Validity of the physical activity scale for the elderly (PASE): according to energy expenditure assessed by the doubly labeled water method. $J$ Clin Epidemiol. 1997;50(5):541-546.

21. Loland NW. Reliability of the physical activity scale for the elderly (PASE). Eur J Sport Sci. 2002;2(5):1-12.

22. Hagiwara A, Ito N, Sawai K, Kazuma K. Validity and reliability of the physical activity scale for the elderly (PASE) in Japanese elderly people. Geriatr Gerontol Int. 2008;8(3):143-151.

23. Choe M-A, Kim J-I, Jeon M-Y, Chae Y-R. Evaluation of the Korean version of physical activity scale for the elderly (K-PASE). Korean $J$ Women Health Nurs. 2016;16(1):47-59.

24. Ngai SP, Cheung RT, Lam PL, Chiu JK, Fung EY. Validation and reliability of the physical activity scale for the elderly in Chinese population. $J$ Rehabil Med. 2012;44(5):462-465.

25. Ku P-W, Sun W-J, Chang C-Y, Chen L-J. Reliability and validity of the Chinese version of the physical activity scale for the elderly. Med Sci Sports Exerc. 2013;15(3):309-319.

26. Casartelli NC, Bolszak S, Impellizzeri FM, Maffiuletti NA. Reproducibility and validity of the physical activity scale for the elderly (PASE) questionnaire in patients after total hip arthroplasty. Phys Ther. 2015;95(1):86-94.

27. Ayvat E, Kilinc M, Kirdi N. The Turkish version of the physical activity scale for the elderly (PASE): its cultural adaptation, validation, and reliability. Turk J Med Sci. 2017;47(3):908-915.

28. Ismail N, Hairi F, Choo WY, Hairi NN, Peramalah D, Bulgiba A. The physical activity scale for the elderly (PASE): validity and reliability among community-dwelling older adults in Malaysia. Asia Pac J Public Health. 2015;27(8 Suppl):62S-72S. 
29. Beaton DE, Bombardier C, Guillemin F, Ferraz MB. Guidelines for the process of cross-cultural adaptation of self-report measures. Spine (Phila Pa 1976). 2000;25(24):3186-3191.

30. Alhamdan AA, Alshammari SA, Al-Amoud MM, et al. Evaluation of health care services provided for older adults in primary health care centers and its internal environment. A step towards age-friendly health centers. Saudi Med J. 2015;36(9):1091-1096.

31. Terwee CB, Bot SD, de Boer MR, et al. Quality criteria were proposed for measurement properties of health status questionnaires. J Clin Epidemiol. 2007;60(1):34-42.

32. Schaubert KL, Bohannon RW. Reliability and validity of three strength measures obtained from community-dwelling elderly persons. J Strength Cond Res. 2005;19(3):717-720.

33. Podsiadlo D, Richardson S. The timed "Up \& Go": a test of basic functional mobility for frail elderly persons. J Am Geriatr Soc. 1991;39(2): $142-148$.

34. Steffen TM, Hacker TA, Mollinger L. Age- and gender-related test performance in community-dwelling elderly people: six-minute walk test, berg balance scale, timed up \& go test, and gait speeds. Phys Ther. 2002;82(2):128-137.

35. Cheng MF, Chen YY, Jang TR, Lin WL, Chen J, Hsieh KC. Total body composition estimated by standing-posture 8-electrode bioelectrical impedance analysis in male wrestlers. Biol Sport. 2016;33(4): 399-405.

36. Bland JM, Altman DG. Cronbach's alpha. BMJ. 1997;314(7080):572.

37. Bland JM, Altman DG. Agreement between methods of measurement with multiple observations per individual. J Biopharm Stat. 2007;17(4): 571-582.

38. Terwee CB, Mokkink LB, van Poppel MN, Chinapaw MJ, van Mechelen W, de Vet HC. Qualitative attributes and measurement properties of physical activity questionnaires: a checklist. Sports Med. 2010;40(7):525-537.
39. Atkinson G, Nevill AM. Statistical methods for assessing measurement error (reliability) in variables relevant to sports medicine. Sports Med. 1998;26(4):217-238.

40. Bland JM. Minimal detectable change. Phys Ther Sport. 2009;10(1):39; author reply 39-40.

41. Ainsworth BE, Haskell WL, Whitt MC, et al. Compendium of physical activities: an update of activity codes and MET intensities. Med Sci Sports Exerc. 2000;32(9 Suppl):S498-S504.

42. Liu RD, Buffart LM, Kersten MJ, et al. Psychometric properties of two physical activity questionnaires, the AQuAA and the PASE, in cancer patients. BMC Med Res Methodol. 2011;11:30.

43. Svege I, Kolle E, Risberg MA. Reliability and validity of the physical activity scale for the elderly (PASE) in patients with hip osteoarthritis. BMC Musculoskelet Disord. 2012;13:26.

44. Smee D, Pumpa K, Falchi M, Lithander FE. The relationship between diet quality and falls risk, physical function and body composition in older adults. J Nutr Health Aging. 2015;19(10):1037-1042.

45. Sallis JF. Age-related decline in physical activity: a synthesis of human and animal studies. Med Sci Sports Exerc. 2000;32(9):1598-1600.

46. Verbunt JA, Sieben JM, Seelen HA, et al. Decline in physical activity, disability and pain-related fear in sub-acute low back pain. Eur J Pain. 2005;9(4):417-425.

47. Fries JF. Physical activity, the compression of morbidity, and the health of the elderly. J R Soc Med. 1996;89(2):64-68.

48. Kowalski K, Rhodes R, Naylor PJ, Tuokko H, MacDonald S. Direct and indirect measurement of physical activity in older adults: a systematic review of the literature. Int J Behav Nutr Phys Act. 2012;9:148.
Clinical Interventions in Aging

\section{Publish your work in this journal}

Clinical Interventions in Aging is an international, peer-reviewed journal focusing on evidence-based reports on the value or lack thereof of treatments intended to prevent or delay the onset of maladaptive correlates of aging in human beings. This journal is indexed on PubMed Central, MedLine,

\section{Dovepress}

CAS, Scopus and the Elsevier Bibliographic databases. The manuscript management system is completely online and includes a very quick and fair peer-review system, which is all easy to use. Visit http://www.dovepress. com/testimonials.php to read real quotes from published authors. 